\title{
Self-regulatory Processes as Mediators of the Relationship between Perceived Partner Responsiveness and Prosocial Organizational Behaviors
}

\author{
LOS PROCESOS DE AUTORREGULACIÓN COMO MEDIADORES DE LA RELACIÓN ENTRE LA SENSIBILIDAD \\ PERCIBIDA EN LA PAREJA Y COMPORTAMIENTOS ORGANIZACIONALES PROSOCIALES
}

\author{
Aline Tonetto da Rosa', Wagner de Lara Machado², Manoela Ziebell de Oliveira ${ }^{3}$ \\ 1. Yara Brasil. \\ 2. Pontificia Universidade Católica de Campinas. \\ 3. Pontifícia Universidade Católica do Rio Grande do Sul.
}

\begin{abstract}
Introduction: The number of publications related to prosocial organizational behaviors (POB) increased in the past years. However, only a small number of studies focus on the intrapersonal process associated with these individual differences. Goals: The present article investigated the mediation role that three self-regulatory processes (SRP) play on the relationship between POB and perceived partner responsiveness (PPR). Method: Participants were 206 Brazilian professionals (56 \% women), with mean age of 34.4 years ( $\mathrm{SD}=9.16$ years), hired in different organizations, who answered an online survey. Most participants worked in the services (31.1\%) and industry (27.7\%) fields. Data provided was analyzed using Structural Equation Modeling. Results: SRP help to understand the interpersonal relationships at the work place in their complexity. They also stress the need to help professionals to be aware of the existence of SRP and the ways in which they influence their behaviors. Discussion: SRP might interfere significantly, for example, on how the PPR contributes to promote POB. Conclusions: Our findings encourage researchers to pay closer attention to the relationship between the constructs of PPR and POB in the future, and to explore other possible mediating or moderating variables within the larger social network of organizations.
\end{abstract}

Keywords: INTERPERSONAL RELATIONS; WORKING ENVIRONMENT; PSYCHOLOGICAL FEEDBACK; SELF-REGULATORY PROCESSES; PROSOCIAL ORGANIZATIONAL BEHAVIORS.

\section{RESUMEN}

Introducción: El número de publicaciones relacionadas con los comportamientos organizacionales prosociales (POB) aumentó en los últimos años. Sin embargo, sólo un pequeño número de estudios se centran en el proceso intrapersonal asociado a las diferencias individuales. Objetivos: El presente artículo investigó el papel de mediación que los procesos de autorregulación (SRP) juegan en la relación entre POB y la sensibilidad percibida en la pareja (PPR). Método: Fueron participantes 206 profesionales brasileños (56\% mujeres), con edad media de 34,4 años ( $S D=9.16$ años), contratados por diferentes organizaciones, que respondieron a una encuesta en línea. La mayoría trabajaban en servicios $(31,1 \%)$ e industria $(27,7 \%)$. Los datos fueron analizados con modelos de ecuaciones estructurales. Resultados: SRP ayudan a entender las relaciones interpersonales en el lugar de trabajo en su complejidad. También afirman la necesidad de ayudar a los profesionales a ser conscientes de la existencia de SRP y la forma en que influyen en sus comportamientos. Discusión: SRP puede interferir significativamente, por ejemplo, sobre cómo el PPR contribuye a promover POB. Conclusiones: Es necesario prestar más atención a la relación entre los constructos de PPR y POB en el futuro, y explorar otros de sus mediadores y moderadores en las organizaciones.

(Tonetto da Rosa A, Machado W, Ziebell de Oliveira M, 2016. Selfregulatory Processes as Mediators of the Relationship between Perceived Partner Responsiveness and Prosocial Organizational Behaviors. Cienc Trab. Ene-Abr; 18 [55]: 9-15).

Palabras clave: RELACIONES INTERPERSONALES, AMBIENTE DE TRABAJO, FEEDBACK PSICOLÓGICO; PROCESOS DE AUTORREGULACIÓN; COMPORTAMIENTOS ORGANIZACIONALES PROSOCIALES.
Correspondencia / Correspondence:

\section{Manoela Ziebell de Oliveira}

Programa de Pós-Graduação em Psicologia,

Pontificia Universidade Católica do Rio Grande do Sul

Av. Ipiranga, 6681 - Prédio 11 - Sala 936; 90619-900

Porto Alegre - RS - Brazil

e-mail: manoela.ziebell@gmail.com

Phone/Fax +55 51 3320-7747

Recibido: 14 de diciembre de 2015 / Aceptado: 22 de febrero de 2016

\section{INTRODUCTION}

The first scientific publications about prosocial organizational behavior (POB) were credited to classical management theorists and practitioners. As observed, some constructive, cooperative behaviors extend beyond an employee's job requirements contributing significantly to the successful functioning of an organization. ${ }^{1}$ Over the last decades, extra-role, helping behaviors, such as volunteering for doing tasks that are not required, have captured the attention of organizational researchers. ${ }^{2}$

Despite the fact that POB-related publications increased 10-fold from 1983 to $1993,{ }^{3}$ empirical investigations have predominantly 
focused on identifying its antecedents and out $\neg$ comes at the expense of exploring conceptual issues. ${ }^{4}$ Indeed, meta-analyses ${ }^{3}$ describe a wide selection of antecedents that usually fall into two broad classes: 1) job attitudes, such as job satisfaction, or 2) individual differences, such as self-regulation processes and perceived partner responsiveness. ${ }^{5}$ However, only a small number of studies focus on the intrapersonal processes associated with these. ${ }^{4,6}$

Although previous research provide substantial support for a positive relationship between job attitudes, as well as for individual differences and various forms of $\mathrm{POB}$, evidence for the intrapersonal phenomena involving $\mathrm{POB}$ is less straightforward. ${ }^{4}$ The weak and inconsistent relationships reported took some authors to suggest that such inconsistency is due to the difficulty to identify and develop accurate measures of POB. ${ }^{7}$ Others, sustained an even more dramatic position: that intrapersonal processes do not have a direct impact on POB. ${ }^{5}$ Nevertheless, this debate clearly indicates the need for more theoretical and empirical research about the topic.

In the present article we will explore existing literature about the relationships between $\mathrm{POB}$, social exchanges, self-regulatory processes (SRP), and job attitudes. We will also discuss problems in conceptualization and in the measures adopted to assess those phenomena in previous studies. Finally, we will propose a predicting model of the impact of Self-Enhancement (SE), Self-Assessment (SA), and Self-Improvement (SI) on the relationship between prosocial organizational behavior (POB) and perceived partner responsiveness (PPR). The model will also consider the contribution of job satisfaction (SAT) in promoting POB.

\section{Conceptual framework and research hypotheses}

PPR is defined as the feeling of being understood, validated and taken care of, even when the other person is not present. ${ }^{8}$ Such definition comprises three main assumptions: 1) interpersonal processes must be conceptualized as dyadic and interdependent; 2) feeling supported is more important than being supported; and 3) the partner is perceived to be aware of and supportively responsive to the central defining features of the self.

Originally, studies about PPR focused on intimacy and close relationships. ${ }^{8,9}$ More recently, researchers have been considering it relevant also to other sorts of relationships. ${ }^{10}$ However, we have not found studies that explore PPR in work settings, even though mutual trust, respect, and commitment are considered necessary to promote high quality relationships and, therefore, POB. ${ }^{11}$ Some studies have shown a moderately positive correlation $(\mathrm{r}=0.37)$ between $\mathrm{POB}$ and the high quality relationship of leaders with their subordinates, as well as among coworkers. ${ }^{12}$ Therefore, we hypothesize that:

Hypothesis 1: PPR will exert a direct positive influence on POB. Other important antecedents of $\mathrm{POB}$ will be investigated in this study: the SRPs, which consist in a unique human ability to constantly think about and represent oneself in one's mind and to others in an abstract way. ${ }^{13}$ Such processes compose a dynamic system, in which the information provided by the partner's behavior helps the individual to act adaptively. ${ }^{9}$ Therefore, SRPs influence how information about the self, obtained in the interaction with others, is selected, evaluated and used to make inferences and to plan the future. ${ }^{13}$ These processes might involve negotiating and modifying self-attributes and skills in order to adapt to reality. Three key SRPs will be investigated in our study: self-enhancement (SE), self-assessment (SA) and self-improvement (SI). ${ }^{13} \mathrm{SE}$ is the tendency to perceive and to present the self to others in the most positive way. ${ }^{14}$ There are two reasons why the individuals act this way: 1) to increase its positivity and be perceived as someone who is worthwhile; and 2) to compensate negative self-views. SA is the tendency to seek accurate, and diagnostic information about the self in order to minimize uncertainty about it. ${ }^{14}$ Finally, SI is the tendency to act in order to adapt and improve individual's attributes, skills and well-being. ${ }^{14}$ For this, it influences strategic decisions in relation to the development of self attributes and skills. While the last SRP promotes genuine improvement without worrying about the consistency and accuracy of information, the other two just act to ensure these aspects. ${ }^{14}$ Considering the influence that SRPs might exert over POB, we hypothesize that:

Hypothesis 2: SE will influence positively $P O B$.

Hypothesis 3: SA will influence positively $P O B$.

Hypothesis 4: SI will influence positively $P O B$.

Hypothesis 5: The direct positive influence of PPR over POB will be mediated by the SRPs in both the relationship with the supervisor and with a coworker of same hierarchical level.

According to the literature, SE, SA and SI coexist and seek, ultimately, to increase the positive perception of the self. That happens either when the self receives positive feedbacks that enhance selfconcept (SE itself) or by the activation of other regulatory processes (tactical SE). The core aspects that define which of the SRP prevail over the others in different situations are: 1) relevance of self-attributes; 2) affect and valence related to the attribute, 3) availability of cognitive and coping resources, 4) social factors, 5) cultural context, and 6) individual differences. ${ }^{13}$ Considering the interaction between the three SRPs, we hypothesize that:

Hypothesis 6: SA and SI will influence positively $S$.

Literature about SRPs has pointed PPR as one of its most important antecedents. For example, in order to increase its positivity (SE), the self has to perceive the others in a positive manner and treat them in a way that displays responsiveness and benefits to both parties. Regarding the attempt to reduce uncertainties (SA), the self has to perceive that the other person is concerned about its welfare and has an accurate perception of its attributes. Studies evaluating this condition show that individuals tend to ignore feedback provided by someone who has an erroneous understanding of them. Finally, when it comes to the effort to improve selfattributes and skills (SI), individuals have to believe that the other person recognizes their goals and is actively engaged in helping them to achieve such goals. ${ }^{9}$ Taking into consideration the influence that PPR might exert over SRPs it is hypothesized that: Hypothesis 7: PP will influence positively SE, SA and SI.

Finally, job satisfaction is considered the most important antecedents of POB. ${ }^{12,3}$ Meta-analyzes about the relationship between these two variables have reported correlations that varied from $\mathrm{r}=0.14$ to $\mathrm{r}=0.31$, depending on how much the constructs were matched by level of specificity. ${ }^{15}$ Considering the previous results, we hypothesize that:

Hypothesis 8: SAT will influence positively $P O B$.

\section{MATERIALS AND METHOD}

\section{Participants}

This study included 206 Brazilian professionals working in different fields. Selection criteria for the study were that the participants: 1) had completed high school; 2) were employed by one organization at the moment of data collection; and 3) had at least one coworker of same hierarchical level, and one supervisor. The 
sample aged between 18 and 70 years $(\mathrm{M}=34.4, \mathrm{SD}=9.16)$ and was composed mainly by women (56.3\%). Most of the participants worked in the services (31.1\%) and industry (27.7\%) fields and they held different positions in different organizations.

\section{Instruments}

Sociodemographic questionnaire: included questions about: sex, age, education, current position and company's segment.

Work-related Self-regulatory Processes Scale (WR-SRP Supervisor) ${ }^{14}$ : uses 14 items to evaluate the SRPs (SE, SA, and SI) present in social interactions with supervisors at the workplace. It that must be answered using a seven point Likert scale ( $1=$ never, and 7 = always) to indicate how often specific situations occur in the interaction with the supervisor. The scale was developed to assess three main SRP: 1) Self-enhancement $(\alpha=0.88$; sample item: The verbal and/or not verbal feedback you receive from your supervisor makes you feel that you are a professional who is responsible at work); 2) Self-assessment $(\alpha=0.85$; sample item: The verbal and/or not verbal feedback you receive from your supervisor helps you to have a clearer view about how responsible you are at work); 3) Self-improvement ( $\alpha=0.91$; sample item: The verbal and/or not verbal feedback you receive from your supervisor helps you to figure out how to improve your level of responsibility at work).

Work-related Self-regulatory Processes Scale (WR-SRP Coworker) ${ }^{14}$ : uses 14 items to evaluate the SRPs (SE, SA, and SI) present in social interactions between coworkers of same hierarchical level at the workplace. It must be answered using a seven point Likert scale ( $1=$ never, and 7 = always) to indicate how often specific situations occur in the interaction with the coworker of same hierarchical level with whom the participant interacts more frequently. The scale was developed to assess three main SRP: 1) Self-enhancement $(\alpha=0.86$; sample item: The verbal and/or not verbal feedback you receive from your supervisor makes you feel that you are a professional who is organized at work); 2) Self-assessment ( $\alpha=0.81$; sample item: The verbal and/or not verbal feedback you receive from your supervisor helps you to have a clearer view about how organized you are at work); 3) Self-improvement ( $\alpha=0.90$; sample item: The verbal and/or not verbal feedback you receive from your supervisor helps you to figure out how to be more organized at work).

Perceived Partner Responsiveness Scale (PPRS): developed based on the list of 18 responsiveness items proposed by Reis ${ }^{9}$. Is composed of six items that assess three factors which characterize a responsive relationship: feeling validated feeling understood, and feeling that personal needs are being met. Each item must be answered using a seven point Likert scale ( $1=$ never, 7 = always) to indicate how frequently the participant feels what the item indicates. A sample item is: When you interact with your COLEAGUE and your SUPERVISOR you use to feel that (s)he understands you.

Job satisfaction Questionnaire S20/23 ${ }^{16}$ : consists of 20 items that must be answered using a seven point Likert scale $(1=$ not at all, and 7 = totally) to indicate how satisfied the participant is in relation to three factors: hierarchical relation satisfaction (sample item: opportunity to make autonomous decisions about one's own work); work environment satisfaction (sample item: illumination at the work environment); and work intrinsic satisfaction and professional growth opportunities (sample item: opportunities to do things you like at the work context). Coefficients alpha were above 0.77 for all three subscales. In the present study only the items 16, 17, 18, 19, 21 and 22, which composed the subscale satisfaction with the hierarchical relation, were used as a measure of job satisfaction.
Prosocial Organizational Behavior Scale (POBS): developed to evaluate $\mathrm{POB}$ in the present study based on the Organizational Civism Scale. ${ }^{17}$ The POBS is composed by 10 items that must be answered using a seven point Likert scale ( $1=$ never $7=$ always $)$ to indicate the frequency that a specific situation occurs in the interaction with the supervisor and in the interaction between coworkers of same hierarchical level level (sample item: You offer to help when s/ he is having difficulties at work).

\section{Procedures}

The research project was submitted to the Ethics Committee of the Universidade Federal do Rio Grande do Sul, and approved under number 2008083. Once this step was concluded, electronic invites with a brief description of the goals and requirements to participate on the research were sent to several professionals. Upon loading the data collection website, all participants were presented a page containing an informed consent, which was completed by the phrase "In view of the above considerations, I, freely and informedly, manifest my interest in participating in the research". To proceed to the survey, which contained the instruments described above, participants had to click the button that read "I agree". In the same Internet address in which participants answered the survey instruments was provided a copy of the informed consent form that could be read and printed by downloading a file in pdf format.

\section{Data analysis}

Before analyzing data generated online, all missing values were replaced by the median of the group in each variable. The scales were then modified and reduced into parcels grouped according to semantic criteria - content - in order to form the indicators of the latent variables - constructs - ${ }^{18}$ After that, confirmatory factorial analyses were conducted with the software Analysis of Moments Structures (AMOS). The reliability of each scale's measurement model was calculated using the Maximum Likelihood estimation method. Then, using SPSS, Pearson correlation analyses were conducted between $\mathrm{POB}$ and five variables, for both coworker and supervisor models: PPR, SE, SI, SA, and SAT. This procedure was used to select variables that had significant correlations with $\mathrm{POB}$ to compose the structural model.

The structural models were built, using AMOS, in accordance with the basic hypotheses of the study about the relationship with supervisors and between coworkers of same hierarchical level. The adjustment indexes for Maximum Likelihood estimation evaluated in the present study were: Goodness of Fit Index (GFI), Adjusted Goodness of Fit Index (AGFI), Tucker-Lewis Index (TLI), Comparative Fit Index (CFI), Root Mean Square Error of Approximation (RMSEA) and Expected Cross-validation Index (ECVI). For the last two indexes, small values designate close fit to data, while to all remaining indexes, values equal or above .90 indicate optimal fit. Respecifications of the original model followed indications of the Modification Indexes (M.I.). ${ }^{18}$

\section{RESULTS}

Reliability indexes of the measurement models for each scale are presented in Table 1. The results suggest that all indicators are appropriate to represent the constructs on the structural model. Also, as can be noted in Table 2, all variables have significant relationship with $\mathrm{POB}$, suggesting the appropriateness of theirin- 
Table 1.

Maximum Likelihood Fit Indexes for Measurements Models.

\begin{tabular}{|c|c|c|c|c|c|}
\hline \multirow[t]{2}{*}{ Scales } & \multicolumn{5}{|c|}{ Fit Indexes } \\
\hline & $\alpha$ & GFI & AGFI & CFI & RMSEA \\
\hline PPR & 0.90/0.89 & $0.95 / 0.95$ & $0.84 / 0.83$ & $0.97 / 0.96$ & $0.143 / 0.144$ \\
\hline SAT & 0.89 & 0.95 & 0.88 & 0.97 & 0.107 \\
\hline POB & $0.90 / 0.85$ & $0.92 / 0.92$ & $0.83 / 0.86$ & $0.93 / 0.91$ & $0.116 / 0.102$ \\
\hline SRP & $0.94 / 0.92$ & $0.99 / 0.97$ & $0.97 / 0.94$ & 1.0/0.99 & $0.000 / 0.057$ \\
\hline SE & $0.89 / 0.85$ & & & & \\
\hline SI & $0.92 / 0.92$ & & & & \\
\hline SA & $0.94 / 0.90$ & & & & \\
\hline
\end{tabular}

Note: $\alpha=$ Cronbach's Alpha. PPR $=$ Perceived Partner Responsiveness; SAT= Satisfaction; POB= Prosocial Organizational Behavior; $\mathrm{SRP}=$ Self-regulatory processes; $\mathrm{SE}=$ Self-enhancement; $\mathrm{Sl}=$ Self-improvement; $\mathrm{SA}=$ Self-assessment. In cells, which contain more than one value, the first indicates the indexes for supervisor scales and the second indicates de indexes for coworker scales.

Table 2.

Pearson's Correlations between Variables in Model.

$\begin{array}{lcccccc}\text { Variable } & 1 & 2 & 3 & 4 & 5 & 6 \\ \text { 1-PPR } & & 0.68 & 0.57 & 0.61 & 0.59 & 0.67 \\ \text { 2-SE } & 0.56 & & 0.56 & 0.73 & 0.49 & 0.68 \\ \text { 3-SI } & 0.45 & 0.37 & & 0.67 & 0.40 & 0.44 \\ \text { 4-SA } & 0.48 & 0.62 & 0.65 & & 0.49 & 0.60 \\ \text { 5-SAT } & 0.33 & 0.32 & 0.18^{*} & 0.27 & & 0.49 \\ \text { 6-POB } & 0.51 & 0.57 & 0.35 & 0.43 & 0.31 & \end{array}$

Note: PPR = Perceived Partner Responsiveness; SE= Self-enhancement; SI= Self-improvement; $\mathrm{SA}=$ Self-assessment; $\mathrm{SAT}=$ Satisfaction; $\mathrm{POB}=$ Prosocial Organizational Behavior. ${ }^{*} p \leq .05$. For all remaining correlations $p \leq .001$ two tailed. Correlations between variables in the model of coworkers are presented in the down-diagonal, while the correlations of the supervisor model are presented in the upper-diagonal.

clusion in the models of the relationship with the supervisor and between coworkers of same hierarchical level.

The next step was modeling relations between variables according to the hypotheses tested in this study. Figure 1 and Figure 2 illustrate the Maximum Likelihood fit indexes for the basic hypothesized structural models for relationships with the supervisor, as well as between coworkers of same hierarchical level, respectively. Only the structural part of the models is presented in order to assure a clearer description of the results. The indexes of adjustment showed a lack of fit for both models in relation to data. It is important to note that some independent variables, which showed significant correlations with POB (see Table 2), had

Figure 1.

Basic hypothesized model for relationships with the supervisor.

$$
\begin{array}{ll}
\mathrm{X}^{2}=321.60 & \mathrm{TL}=0.89 \\
\mathrm{Df}=94 & \mathrm{CFI}=0.91 \\
\mathrm{GFI}=0.85 & \mathrm{ECVl}=1.98(90 \% \mathrm{C} . \mathrm{I}=1.73-2.26) \\
\mathrm{AGFI}=0.79 & \mathrm{RMSEA}=0.109(90 \% \mathrm{C} . \mathrm{I}=0.096-0.122), p \leq 0.001
\end{array}
$$

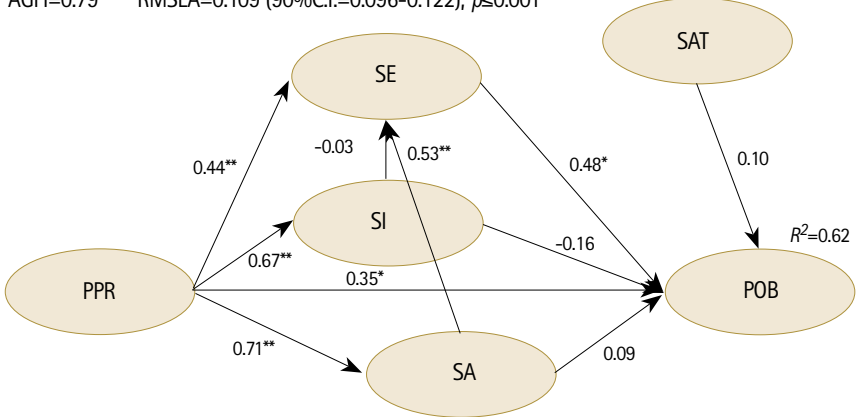

$\mathrm{PPR}=$ Perceived Partner Responsiveness; $\mathrm{SAT}=$ Satisfaction; $\mathrm{POB}=$ Prosocial Organizational Behavior; SE= Self-enhancement; $S \mathrm{I}=$ Self-improvement; $\mathrm{SA}=$ Self-assessment. ${ }^{*} p \leq .05,{ }^{* *} p \leq .001$, for all remaining regression paths $p>05 . R^{2}=$ portion of $\mathrm{POB}$ variance explained for its predictors.

Figure 2.

Basic hypothesized model for the relationship between coworkers.
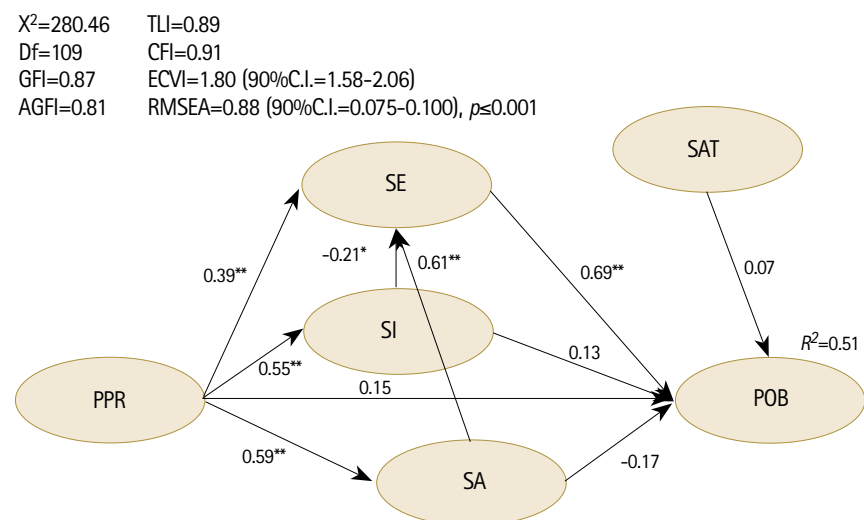

PPR = Perceived Partner Responsiveness; SAT = Satisfaction; $\mathrm{POB}=$ Prosocial Organizationa Behavior; $\mathrm{SE}=$ Self-enhancement; $\mathrm{SI}=$ Self-improvement; $\mathrm{SA}=$ Self-assessment ${ }^{*} \mathrm{p} \leq .001$, for al remaining regression paths. $\mathrm{p}>.05 . R^{2}=$ portion of $\mathrm{POB}$ variance explained for its predictors.

no explanatory power in relation to this variable when controlling for other independent variables included in the model. This happened to the variables SAT and SA in the relationship with the supervisor and to the variables SAT, SA and SI in the relationship between coworkers of same hierarchical level.

After analyzing results, respecifications of the models were made. The variable SAT was excluded of both models since it did not have a significant relation with $\mathrm{POB}$. According to the values of the modification indexes (M.I.), the regression path from SI to SE was eliminated from the supervisors' model. Respecifications related to the error and residual terms were not done, since the goal of adjust was to investigate the plausibility of the clean hypothesized models and not necessarily to improve their fit. The Maximum Likelihood fit indexes for the respecified models of the relationship with the supervisor and between coworkers of same hierarchical level are presented, respectively, on Figure 3 and Figure 4. All adjust indexes (GFI, AGFI, TLI e CFI) had a significant increase, and residual values were lower for the adjusted models (RMSEA e ECVI) suggesting their appropriateness. It is also possible to notice that the exclusion of independent variables results in a small increase of the variance explained by $\mathrm{POB}$ in both models.

Figure 3.

Respecified model for the relationship with the supervisor.

$$
\begin{array}{ll}
X^{2}=148.05 & \mathrm{TLI}=0.95 \\
\mathrm{Df}=68 & \mathrm{CFI}=0.96 \\
\mathrm{GFI}=0.91 & \mathrm{ECVI}=1.08(90 \% \text { C.I }=0.93-1.27) \\
\mathrm{AGFI}=0.86 & \mathrm{RMSEA}=0.076(90 \% \text { C.I. }=0.059-0.092), \quad p \leq 0.007
\end{array}
$$

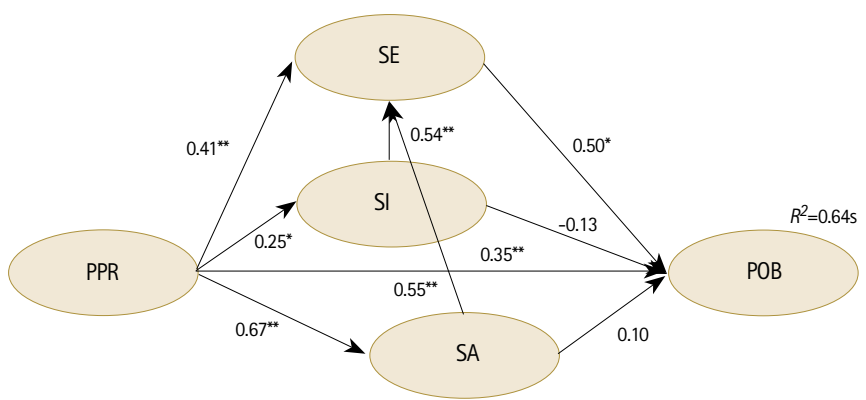

PPR = Perceived Partner Responsiveness; $\mathrm{POB}=$ Prosocial Organizational Behavior; $\mathrm{SE}=$ Selfenhancement; $\mathrm{SI}=$ Self-improvement; $\mathrm{SA}=$ Self-assessment. $p \leq .05,{ }^{* *} p \leq .001$, for all remaining regression paths $p>05 . R^{2}=$ portion of $\mathrm{POB}$ variance explained for its predictors. 
Figure 4.

Respecified model for the relationship between coworkers.

$\begin{array}{ll}X^{2}=155.18 & \text { TLI }=0.94 \\ D f=80 & C F I=0.96 \\ G F I=0.91 & E C V I=1.15(90 \% C . I=0.99-1.34) \\ \text { AGFI }=0.87 & \text { RMSEA }=0.068(90 \% \text { C.I. }=0.052-0.084), p=0.04\end{array}$

AGFI $=0.87 \quad$ RMSEA $=0.068(90 \%$ C. $I=0.052-0.084), p=0.04$

\section{PPR}

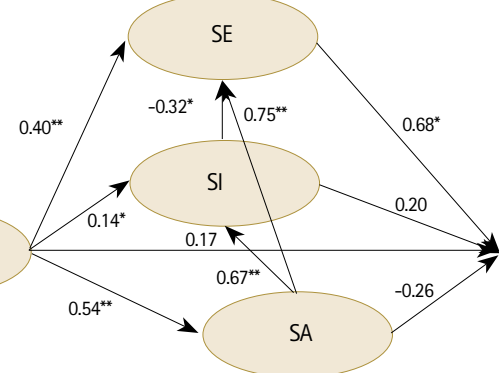

$\mathrm{PPR}=$ Perceived Partner Responsiveness; $\mathrm{POB}=$ Prosocial Organizational Behavior; SE $=$ Selfenhancement; $S \mathrm{~S}=$ Self-improvement; $S A=$ Self-assessment. ${ }^{*} p \leq .05,{ }^{* *} p \leq .001$, for all remaining regression paths $p>05 . R^{2}=$ portion of $\mathrm{POB}$ variance explained for its predictors.

Results presented indicate the plausibility of both models as representations of the hypothesized relationships between the constructs investigated by the present study. More specifically, Hypothesis 1 predicted that SAT would have a positive direct influence over POB, which was rejected in both models. On the other hand, Hypothesis 2, which predicted that SE would have a positive, direct influence over POB, was confirmed, showing it to be the best predictor of POB. Differently, Hypotheses 3 and 4, which predicted that SA and SI would have a positive direct influence over POB, were rejected. When looking exclusively to the interactions between SRP represented by Hypothesis 5, which predicted that SA and SI would have a positive direct influence over SE, was partially confirmed in both models. While SA showed the expected influence over SE in both models, SI exerted a negative direct influence over SE in the coworker model and no influence over SE in the supervisor model. Besides that, PPR had a significant and positive influence on SE, SA and SI, for both models, as pointed in the Hypothesis 6. The main effect was observed between PPR and SA, in both models. Similarly to Hypothesis 5, the relation between PPR and POB (Hypothesis 7) depend on which relationship is being analyzed: with the supervisor or between coworkers of same hierarchical level. On the first situation, PPR exerts a small positive direct influence over POB. On the second situation, though, the same hypothesis was totally rejected. According to these results, Hypothesis 7 was just partly confirmed. Taken together, the aforementioned results support Hypothesis 8, central to the present study, which states that the relation between PPR and POB would be mediated by self-regulatory processes (SRP) in both models. More specifically, the analyses conducted helps to identify that the main flow of influences goes from PPR to POB through SA and SE, respectively.

\section{DISCUSSION}

The main goal of this study was to evidence the impact of SRPs on the relationship between POB and PPR - considered as one of the core features of social exchanges in the workplace. Two different models provided evidence of the mediating role occupied by SRPs, in social exchanges at work, both between coworkers of same hierarchical level and between employees and their supervisors. The bivariate correlational analysis between POB and the variables PPR, SRP and SAT stressed the importance to include all of them in the models (see Table 2), as suggested by the literature. ${ }^{3,4,19}$ However, when all the hypothesized relations were evaluated simultaneously by the SEM model, the variables SAT, SA and SI did not show significant relationships with POB in any of the models. Differently, PPR showed significant relationships with $\mathrm{POB}$ only in the supervisor model.

Based on the literature about the relationship between POB and job satisfaction, it was expected that professionals who feel that they are being treated fairly by their supervisors would reciprocate their supervisors and co-workers through POB. ${ }^{12,15}$ Surprisingly, this did not happen. One plausible explanation for the lack of such relationship, in the co-worker model, might be that helping co-workers might go unnoticed by supervisors or the organization. Besides, investing significant time and energy in inter $\neg$ personal POB, such as helping others, can sometimes undermine the accomplishment of the employee's own job duties. ${ }^{7}$

The same could not be affirmed about the supervisor model, once all the items of the job satisfaction instrument focused on the relationship with the supervisor. Taking into consideration the bivariate correlation, it is possible to suppose that the impact of SAT over POB in the supervisor model was minimized by the impact of SA and SI over SE and SE over POB. This means that how the information about the self is selected, evaluated and used tends to be more important than the degree of pleasure obtained from the job to promote POBs directed at the supervisor.

The theoretical assumption that all SRPs seek ultimately to increase the positivity of the self explains two important results. ${ }^{9,13}$ First, SA showed the expected influence over SE. Unexpectedly, the same pattern was not observed in the relationship between SI and SE. In the supervisor model, SI did not exert influence over SE, while in the coworker model it exerted a small negative influence over SE. This might be related to the belief that perceiving a possibility to improve attributes and skills in the interaction with coworkers of same hierarchical level means showing personal weaknesses to possible competitors. ${ }^{20}$ A second important result is that the variables SA and SI exerted only indirect influence over POB through SE in both models. This mediation effect of SI did not occur only in the supervisor model.

SA was the variable that better explained SE in both models. It implies that, in order to know how to increase the positivity of the self, it is necessary first to recognize what are its strengths and weaknesses. Previous studies show that professionals tend to avoid diagnostic information and to reduce inquiry behaviors when performance expectations are low. ${ }^{20}$ This tendency supports the idea that the need to maintain a favorable self-image would take priority over the motivation to correct errors. In general, individuals tend to seek feedback that will enhance their self-view and public-image. ${ }^{20}$

The fact that PPR had a direct significant influence over POB only in the supervisor model might be due to employees' expectations that their supervisor will be responsive to them6 This makes them show POB in retribution. ${ }^{12}$ In other words, when employees perceive that the supervisor honors such expectations under a psychological contract, they are more prone to act cooperatively. ${ }^{4}$ The same support did not seem to be expected by the coworkers of the same hierarchical level. ${ }^{21}$

Among all SRPs, SA was better explained by PPR in both models. 
It is possible that, in order to reconsider their self-perceptions based on the information provided by others, individuals have to feel that the person with whom they interact cares about and respects them the way they are., ${ }^{9,10}$ This means that members of organizations may cooperate with one another by validating the identities they present one another. Failing to honor such identities is often perceived as disrespecting the norms of interpersonal fairness in the organization weakening, this way, feelings of connectedness with others at the workplace. ${ }^{22}$

In sum, in both models the core pattern confirmed the main expectation of the present study: the relation between PPR and POB is mediated by SRPs. In other words, results suggest that as long as professionals feel understood, validated and taken care of, they tend to take the feedback received from coworkers and supervisors into account in order to clarify their self-views (SA). Consequently, there is an increase of the positivity of the self (SE), which makes individuals feel worthwhile and, thus, more capable and confident to help others.

\section{CONCLUSIONS}

The present work has some important theoretical implications. First, it proposed to consider SRPs as mediators of the relationship between high quality social exchanges (PPR), both with the supervisors and with co-workers and POB. Although a fair number of studies has examined the relationships between both of these concepts, little research has investigated their potential mediators, and none of them has explored the mediating role of SRPs. The results obtained in the present study have evidenced that intrapersonal processes, like SA, SE, and SI, help to better understand the interpersonal relationships at the work place in their complexity. A second contribution of the present study is the evidence that PPR is an important antecedent of SE and SA in work relationships. This result confirms what was suggested by previous studies conducted in other contexts. $^{9}$ The same did not happen to SI, once it showed a weak relationship with PPR, differently from what happens in other contexts, according to literature.

Another theoretical contribution of this study is that it was one of the few to investigate the impact of SE, SA and SI over other variables simultaneously. By doing this, it was possible to confirm that, also in the work relationship, SA seeks, ultimately, to increase the positivity of the self.

The present study also has several significant practical contributions. The most important stresses the need to help professionals to be aware of the existence of SRPs and how they impact their behaviors. Among other reasons, because SRP might interfere significantly, for example, on how the perception of responsiveness contributes to promote POB. This means that coworkers should not be concerned only with acting responsively, but also with helping others to identify how SA, SE and SI impact their behavior.

In sum, the present article evidences that organizations can benefit from providing recurrent feedback to their employees and assisting them in using it consistently to improve their weaknesses. This practice should reinforce the perceived responsiveness that might help professionals to obtain a more accurate self-view and, consequently, increase the positivity that might promote prosocial organizational behaviors.

It is important to recognize some limitations of the present study that should be addressed in future research. First, although the same pattern of interactions was observed in respondents occupying different positions at diverse organizations, this was a crosssectional study. Thus, it is not possible to draw firm conclusions about causality. Future longitudinal research could help obtain information about how the variables under investigation and the relationships between them might unfold over time. In order to investigate the pattern of interactions and exchanges over time in more detail, future research could also use methods other than questionnaires, such as observation, diaries and interviews.

A second limitation of the present study that hinders generalizations are the characteristics of the sample. Future research should attempt to replicate this study using larger samples and paying attention to their representativeness. That would allow to conduct comparative studies between professionals who work in different fields (industry, services, health, etc.) and cultural contexts, for example.

Although literature shows great concern about inflated hypothesized relationships caused by common method variance, this could not be avoided in the present study. This is due to the fact that the phenomenon addressed was the personal perception of the professionals about how they interact with other people and how they deal with information received about themselves in those interactions.

To our knowledge, this study was the first to introduce the idea of SRPs as mediators of the relationship between PPR and POB. Although additional research needs to be conducted on this issue, the present study contributes to the research on interpersonal exchange relationships at the workplace by developing and testing a multi-level model that strongly suggests that SRP impact significantly over the relationship between PPR and POB. It is expected that these findings encourage researchers to pay closer attention to the relationship between the constructs of PPR and POB in the future, and to explore other possible mediating or moderating variables within the larger social network of organizations. 


\section{REFERENCES}

1. Katz D. The motivational basis of organizational behavior. Syst Res.1964; 9(2):131-146.

2. Spitzmuller M, Van Dyne L. Proactive and reactive helping: Contrasting the positive consequences of different forms of helping. J Organ Behav. 2012;34(4):560-580

3. Podsakoff PM, MacKenzie SB, Paine JB, Bachrach DG. Organizational Citizenship Behaviors: A critical review of the theoretical and empirical literature and suggestions for future research. J Manage. 2000;26(3):513-563

4. Bolino M, Harvey J, Bachrach D. A self-regulation approach to understanding citizenship behavior in organizations. Organ Behav Human Dec. 2012;119(1):126-139.

5. Lester $\mathrm{S}$, Meglino $B$, Korsgaard $M$. The role of other orientation in organizational citizenship behavior. J Organ Behav. 2008;29(6):829-841.

6. Podsakoff N, Whiting $S$, Podsakoff $P$, Blume B. Individual- and organizational-level consequences of organizational citizenship behaviors: A metaanalysis. J Appl Psychol. 2009;94(1):122-141.

7. Marinova $S$, Moon $H$, Van Dyne L. Are all good soldier behaviors the same? Supporting multidimensionality of organizational citizenship behaviors based on rewards and roles. Hum Relat. 2010;63(10):1463-1485.

8. Reis $\mathrm{H}$. Perceived partner responsiveness as an organizing theme for the study of relationships and well-being. In: Campbell L, Loving $T$, editors. Interdisciplinary Research on Close Relationships: The Case for Integration. Washington, DC: American Psychological Association; 2012. p. 27-52.

9. Reis H. Steps toward the ripening of relationship science. Pers Relationships. 2007;14(1):1-23.

10. Reis H, Gable S. Responsiveness. Curr Opin Psychol. 2015;1:67-71.

11. Raub $S$, Robert $C$. Differential effects of empowering leadership on in-role and extra-role employee behaviors: Exploring the role of psychological empowerment and power values. Hum Relat. 2010;63(11):1743-1770.
12. Ilies R, Nahrgang J, Morgeson F. Leader-member exchange and citizenship behaviors: A meta-analysis. J Appl Psychol. 2007;92(1):269-277.

13. Sedikides C, Strube MJ. Self-evaluation: to thine own self be good, to thine own self be sure, to thine own self be true, and to thine own self be better. Adv Exp Soc Psychol. 1997; 29:209-269.

14. Rosa A, Oliveira M, Machado W, Gomes W. Development of the Self-Regulatory Scale in Work-Related Interactions. Psicol Reflex Crit. 2014;27(2):308-316.

15. Edwards B, Bell S, Arthur, Jr. W, Decuir A. Relationships between Facets of Job Satisfaction and Task and Contextual Performance. Appl Psychol. 2008;57(3):441-465.

16. Carlotto $\mathrm{M}$, Gonçalves Câmara S. Propriedades psicométricas do Questionário de Satisfação no Trabalho (S20/23). PsicoUSF [on line] 2008 [cited 8 0ct 2015];13(2):203-210. Available from: http://www.scielo.br/scielo.php?script= sci_arttext\&pid=S1413-82712008000200007

17. Porto J, Tamayo Á. Escala de valores relativos ao trabalho: EVT. Psic: Teor e Pesq. 2003;19(2):145-152.

18. Byrne B. Structural equation modeling with AMOS. Mahwah, N.J.: Lawrence Erlbaum Assoc; 2010.

19. Bowler W, Halbesleben J, Paul J. If you're close with the leader, you must be a brownnose: The role of leader-member relationships in follower, leader, and coworker attributions of organizational citizenship behavior motives. Hum Resour Manage R. 2010;20(4):309-316.

20. Scholer A, Ozaki Y, Higgins E. Inflating and deflating the self: Sustaining motivational concerns through self-evaluation. J Exp Soc Psychol. 2014;51:60-73.

21. Kamdar D, Van Dyne L. The joint effects of personality and workplace social exchange relationships in predicting task performance and citizenship performance. J Appl Psychol. 2007;92(5):1286-1298.

22. Johnson $R$, Lanaj $K$, Barnes $C$. The good and bad of being fair: Effects of procedural and interpersonal justice behaviors on regulatory resources. J Appl Psychol. 2014;99(4):635-650. 